\title{
RESPUESTAS A PREGUNTAS Y COMENTARIOS
}

\section{Respuestas de William Schwartz}

Estas no son críticas, son observaciones y este fórum es para eso, para escuchar opiniones. Sobre la pregunta en torno a la Ley de Veda y la forestería comunitaria debemos decir que la veda es una ley que surge en 2006, porque en la Región Autónoma Atlántico Sur, y también aquí en el Norte, se abusaba de una normativa que existe en la ley, que se llama Planes Mínimos, que sirve para regular intervenciones en bosques dispersos, no para bosques compactos. Pero muchos empresarios madereros utilizaron la triquiñuela de usar un plan mínimo, para no pagar el costo de hacer extracciones en bosques compactos. El Gobierno de entonces lo permitía. Cuando nosotros (gobierno sandinista) llegamos al poder, INAFOR era una institución desacreditada. En todo este tiempo de gobierno, lo que hemos buscado es cómo lavarle, poco a poco, la cara a esta institución. La cosa explotó cuando en lugares como Kun Kun se encontraron cerca de seis mil tucas de madera preciosa (caoba, cedro real y algo de cedro macho) que se habían talado con permisos de planes mínimos, cuando en realidad eran extracciones en bosques compactos. Como eso se volvió espinoso para el gobierno de entonces, que estaba en el marco de una campaña electoral, entonces elaboraron una ley de veda, sin mucho tecnicismo, sin mucho argumento jurídico. En esta ley eliminan los planes mínimos, eliminan los planes de reposición, prohíben todo plan de manejo, aún los que ya estaban pagados, y eso es lo que heredamos nosotros en el 2007. Tuvimos entonces que sentarnos a dialogar con los madereros, incluso algunas cosas de la ley de vedas, por ejemplo, señalar que la Ley de Vedas, como toda ley, no tiene aplicación retroactiva.

Con respecto a la Ley de Vedas, la institución nuestra (INAFOR) encabezó un movimiento de revisión y reforma a la Ley, para no derogarla, ya que algunos legisladores creen que esta es una Ley modelo y que es la única manera de proteger el bosque. Una idea totalmente equivocada. Tuvimos que jugar con el aspecto técnico y político del asunto. Entonces, para no derogar la ley, lo que propusimos fue una reforma a la Ley. Nosotros como institución nos competía hacer esto, meternos en actividades legislativas, pero lo hicimos en aras del desarrollo forestal y lo mejor para el país. Los empresarios no nos apoyaron, a pesar de ser ellos los afectados.

Contestando la pregunta, nosotros estamos promocionando la forestería comunitaria en los territorios que no cubre la Ley de Vedas. En otros territorios, como en el caso de los ramas, que están cubiertos por la Ley, estamos desarrollando como alternativa otras actividades que tienen que ver también con el bosque (turismo, etcétera).

En cuanto a la pregunta sobre segunda y tercera transformación de la madera, es cierto que es difícil, es cierto. No quiero decir que este gobierno inició la forestería comunitaria. Pero hay que reconocer que tiene la voluntad política, que es lo importante. Ustedes trabajaron solos, tan solos, que a pesar de toda la trayectoria que tienen en forestería, es hasta el año pasado que obtuvieron un aserrío.

Desde el 2002, que trabajan ustedes explotando su bosque, siempre han tenido que pagar por aserrar la madera producida. No fue sino hasta este año que les conseguimos su propio aserrío. Eso es lo importante, quién tiene la voluntad política.

Para hacer que esos talleres funcionen, ya estamos haciendo las coordinaciones para que INATEC capacite a los muchachos, en un primer momento, para que fabriquen sus muebles, y en un segundo momento, para que puedan perfeccionar el acabado y todo lo demás. Es cierto que la forestería comunitaria no nace en Nicaragua con nosotros, pero con nosotros crece y se fortalece muchísimo. Antes se trataba de una actividad de tres comunidades, ahora se trata de cinco bloques de 17 comunidades. Esa es la diferencia.

Ahora bien, no podemos en estos momentos autorizar planes de manejo cuando hay tanta madera caída. Si hay tala de árboles en pie, nosotros no podemos dar cobertura suficiente a esas acciones, ya que algunas delegaciones municipales de INAFOR tienen que cubrir varios municipios. Pero cuando los agarramos, eso sí, les cae el peso de la ley. Y les quiero decir una cosa: cuando capturamos a esos delincuentes, nos llueven cartas. Y 
quiero asegurarles sí, que la tala ilegal que existe ahora en Nicaragua es mucho menos que la existía durante los gobiernos pasados. El gobierno anterior hizo esta ley de vedas para cubrir de esa forma la enorme tala ilegal que existía. Ahora, a quien infringió la ley, le cae el peso de la ley, sin diferencia de quién se trate.

En cuanto a las preguntas de los compañeros mayangnas puedo decirles que el proceso de implementación de la forestería es lento, conllevan un proceso de aprendizaje primero. Y segundo, es un problema económico, falta de recursos. Sin embargo en este año ya está el taller de ebanistería que les habíamos prometido. El compromiso anterior es que le íbamos a entregar un aserrío. Hubo autoridades que nos dijeron que allí no era posible meter un aserrío, porque era un área protegida -y nosotros tenemos que respetar a las instituciones que administran las áreas protegidas. Nosotros administramos las áreas que no son protegidas. Entonces decidimos que debe ser un taller de ebanistería para aprovechar la madera caída y eso es lo que vamos a hacer este año.

Para responder a Rufino, sobre lo de la segunda y tercera transformación. Sí, es cierto. Nosotros comenzamos prácticamente en el 2007 y ustedes comenzaron antes, ustedes son vieja guardia, veteranos, en esto. No queremos decir que el gobierno inició esto, pero hay que reconocer que este gobierno ha tenido la voluntad política, que es lo importante. Ustedes trabajaron solos, tan solos, Rufino, que hasta el ano pasado, a pesar de tener una larga trayectoria, hasta el ano pasado ustedes tuvieron un aserrío y que nosotros estamos preocupados cuando nos propusiste vos tu problema de que no lo habías podido inscribir por razones burocráticas, yo hable con MARENA exhortándoles a aligerar eso, y ya está en proceso de inscripción y todo lo demás. Piensen que estos comunitarios, desde el 2002 son proveedores de madera, $y$ es hasta la fecha ellos tienen que pagar servicio para sacar su madera y aserrarla. Esta próxima zafra ya no pagarán servicio de aserrado, pues tienen su propio aserrío, gracias a la voluntad política del gobierno.

Esto es un proceso, y para hacer que esos talleres de ebanistería funcionen, ya estamos haciendo las coordinaciones con el INATEC, para que capaciten a los muchachos, en un primer momento para que puedan elaborar sus muebles, y, en un segundo momento para que puedan perfeccionar el acabado y todo lo demás. Yo estoy claro que el proceso de forestería no inicia con nosotros, pero se fortalece y crece muchísimo. Hablaban aquí de tres comunidades que comenzaron con la forestería, y ahora estamos hablando de cinco bloques con diecisiete comunidades. Y esa es la gran diferencia, y estamos claros, y me parece que quienes tienen proceso de forestería comunitaria en su país saben que este no es un proceso de hoy a mañana, es un proceso que va a ir caminando con tropiezos, con problemas, con dificultades, con errores y con éxitos también.

Contestando la pregunta de Rubén González sobre la tala en pie quiero decirles que, en esta etapa hay planes generales de manejo solamente en Alamikangban, donde tenemos coníferas que no afectó mucho el huracán. Creo que sería un crimen dar permisos de aprovechamiento, con planes generales de manejo para la tala de árboles en pie en la zona afectada por el huracán, cuando hay muchos millones de árboles caídos.

Y no dudo que existe la tala de árboles en pie, ya que nosotros no podemos vigilar, Pero cuando los agarramos les cae todo el peso de la ley. Y les voy a decir una cosa, cuando capturamos a ésos, nos llueven cartas, cartas habidas y por haber, de todo el mundo, de mucha gente abogando por estos hechores. Pero nosotros no estamos allí para leer cartas, sino para enfrentar estos problemas. Pero lo más importante no es perseguir a la gente, creo que lo importante es el fomento, concientización, educación y todo lo demás. Pero si a pesar de esa concientización, educación y flexibilidad, la gente no acata, entonces, quiero decirles que ser flexibles no quiere decir blandengue y que quien infringió la ley le cae el peso de la ley, sin diferencia de quién es.

Tampoco les puedo asegurar que tenemos milimétricamente vigilado todo el territorio nacional, porque sería mentiroso. Yo creo que en América Latina, uno de los problemas que tenemos que resolver es lo de la tala ilegal. De 153 municipios que tiene el país, nosotros tenemos nombrados 74 delegados municipales, lo que significa que algunas veces algunos delegados municipales tienen que cubrir dos y tres municipios. Entonces, sí puede, o mejor dicho debe haber alguna fuga de tala ilegal. Pero les aseguro que la tala ilegal ahora es menos que la que encontramos en los momentos de sinvergüenzada que hubo en los gobiernos anteriores. Porque eso fue sinvergüenzada, fue falta de ética. Hicieron una Ley de Vedas para cubrir y tirar una cortina de humo sobre un problema que era histórico, de esta institución que se llama INAFOR. Y muchas gracias por las preguntas e intervenciones. 


\section{Respuestas de Harold Wilson}

Con respecto a la Ley de Vedas. Realmente, la forestería comunitaria comenzó a tener relevancia en el Consejo a partir de la Ley de Vedas. El Comité Consultivo Forestal se reunió, en varias ocasiones, para analizar la toma de decisiones con respecto a la Ley de Vedas. En una de las sesiones que hicimos se dieron varios choques. Los que conocen la esta Ley, y aquí la mayoría, existe una contradicción entre muchos de sus artículos. En una parte le da potestad a INAFOR, en otra parte le da al Ejército, en otra parte a la Procuraduría. Tomando en cuenta esta situación, nosotros, cuando estábamos la estrategia a tomar en cuanto a la forestería comunitaria consideramos que el Ejército ni INAFOR ni nadie va a controlar el tema de la tala ilegal si no lo hacen las comunidades mismas. Si las comunidades se apropian de sus recursos y realmente reconocen el valor de ese recurso forestal, entonces, ese problema de la tala ilegal y demás delitos conexos se van a terminar. Por esta razón le dimos mayor énfasis al tema de forestería comunitaria. Aún sigo creyendo que el día que las comunidades valoren sus recursos forestales y hagan un buen manejo de este recurso habrá un mejor control forestal.

Contestando la otra pregunta del compañero sumo de Españolina. Nosotros estamos dispuestos a apoyar a las comunidades. Sin embargo es imposible atender a todas las comunidades como éstas y nosotros queremos. Si consideramos las afectaciones del Huracán veremos en los litorales la afectación que hay en las zonas de la Reserva. Uno de los problemas que tuvimos al trabajar en Españolina, en la organización de la cooperativa, en la capacitación y en todos esos temas fue el problema de la Reserva. No pudimos hacer muchos avances. Sin embargo buscamos la forma de apoyar a Españolina. Uno de los procesos fue la conformación de la cooperativa. Nosotros no olvidamos a la nación mayangna, por eso le facilitamos un aserrío a Wasakin. Pero quiero que entendamos algo. Aquí hay representadas algunas comunidades que tampoco se les dio aserrío, sino que sólo una motosierra. La forestería comunitaria no es eso. Con aserrío o sin aserrío uno puede hacer forestería, y eso lo debemos entender. Simplemente se trata de la voluntad de cada quien de hacer un buen manejo de su recurso forestal. Y haciendo un buen manejo en el marco de la forestería comunitaria vamos a tener bosques por mucho tiempo y vamos a poder cambiar el nivel socioeconómico. de las comunidades. Pero, claro, eso tiene mucho ver con la calidad del liderazgo. Si no encontramos buenos líderes, siempre habrá fracaso en las comunidades. Y esto lo hemos visto en estos dos años que estamos tratando de impulsar la forestería comunitaria, donde hay líderes que están conscientes con este tipo de proceso, el avance es mucho mejor.

Con respecto a lo que mencionaba el compañero Rufino. En las diecisiete cooperativas que estamos mencionando, allí también está incluida Laya Siksa. Quiero decirles que la voluntad del gobierno regional no es solo dar atención a estas 17 pequeñas empresas sino que estamos viendo también las posibilidades de ampliar nuestra atención a un mayor número de comunidades.

Estamos tratando de conformar una corporación donde participen todas estas empresas comunitarias y que puedan así conseguir acompañamiento. Es importante mencionar que la forestería comunitaria en otros países, y aquí también con el ejemplo de Laya Siksa y otras comunidades, ha llevado mucho tiempo: cinco, diez años, y todavía siguen en un proceso bien duro, porque se trabaja con comunidades y hay que estar en un constante acompañamiento, de tal manera que la gente se vaya apropiando de este proceso. Después del paso del Huracán, esto ha sido muy intensivo, y con el apoyo de algunas instituciones como GTZ e INAFOR hemos logrado que marche la forestería comunitaria. Pero estamos claro que de las 17 empresas territoriales formadas, no todas van a tener éxito de forma inmediata. Unas van a tener un mejor avance que otras, de acuerdo al interés que pongan en su empresa. Por otro lado es vital la constancia del acompañamiento, si no, la empresa puede ir al fracaso.

Para este 24 de este mismo mes estableceremos un taller donde lograremos la intervención de las ONG, ya que ha habido experiencia que han pedido financiamiento a nombre de las comunidades y luego se pierden. En este taller queremos saber cuál ha sido el avance en la Forestería comunitaria, para tener mayores luces y tomar las mejores decisiones. El día de ayer formamos la directiva de la Comisión de Regionalización del tema forestal y creo que es un avance del gobierno y una estrategia para ir trabajando. De aquí al 2010 esperamos ver empresas ya formadas.

En cuanto a la pregunta sobre cuáles son los objetivos de esta corporación de empresas comunitarias. La corporación estaría formada por todas estas pequeñas empresas. Esta corporación tendría una parte administrativa, para asistencia técnica, para gestión de mercado y, por supuesto, para busca de créditos. Esta empresa sería el canal de todas esas empresas para la búsqueda de financiamiento. 